\title{
High Frequency Solid State Transformer Design Considerations for Power Systems Applications
}

\section{Raton Kumar Nondy ${ }^{1}$, Md. Abul Bashar ${ }^{1}$, Prema Nondy ${ }^{2}$, M. Hazrat Ali ${ }^{3}$}

\author{
${ }^{1}$ Department of Electrical and Electronic Engineering, International University of Business \\ Agriculture and Technology (IUBAT), Dhaka, Bangladesh \\ ${ }^{2}$ Department of Electrical and Electronic Engineering \\ Bangladesh Army University of Engineering \& Technology (BAUET), Natore, Bangladesh
}

\author{
${ }^{3}$ Department of Electrical and Electronic Engineering \\ European University of Bangladesh (EUB), Dhaka, Bangladesh
}

*Corresponding author: Prema Nondy

\begin{abstract}
The conventional power frequency (50 or $60 \mathrm{~Hz}$ ) transformers are economical, highly reliable and quite efficient but they suffer with certain drawbacks like sensitive to harmonics, voltage drop under load, no protection from system disruptions and overloads, poor performance under dc offset load unbalances and no scope to improve power factor. These transformers with copper wound wires on iron cores are unable to respond to control signals as power generations become distributed and intermittent. So, the need of electronic based regulated power supply with software based remote intelligence has become essential. Also, to easily connect the new energy sources to the grid and to improve the power quality by harmonic filtering, voltage sag correction and highly dynamic control of the power flow, a new type of transformer based on power electronics, known as SST has been introduced. The SST realizes voltage transformation, galvanic isolation, power quality improvements such as instantaneous voltage regulation, voltage sag compensation and power factor correction. It is a collection of high-powered semiconductor components, high frequency power transformer and control circuitry which is used to provide a high level of flexible control to power distribution networks. The SST is a high frequency switched Power Electronic Devices (PEDs) based transformer with high controllability that enables flexible connectivity between existing medium voltage power distribution network, low voltage AC residential system and envisioned DC residential system. In this paper a systematic constructional detail of a SST with a power rating of $2 \mathrm{kVA}$, operating frequency of $20 \mathrm{kHz}$ and voltage rating of $600 / 60 \mathrm{~V}$ as a scaled-down prototype used for power converter topologies is presented. The design is simple and it avoids the difficulty of choosing massive amounts of empirical parameters.
\end{abstract}

Keywords: SST; power electronic devices; SST topology; litzendraht (Litz) wire

\section{INTRODUCTION}

The conventional transformers are the essential elements of the power systems that convert the high-voltage electricity delivered by power lines to the required voltage level needed for consumers and vice-versa at generating stations. Thus, they are widely used in electric power system to perform the primary functions, such as voltage transformation and isolation. They are one of the heaviest and most expensive devices in an electrical system because of the large iron cores and heavy copper windings in the composition. On the other hand, the SST is a collection of high-powered semiconductor components, high frequency power transformers and control circuitry which is used to provide a high level of flexible control to power distribution networks. PEDs can quickly respond to control signals and eliminate the problems linked to conventional transformer as mentioned. The solid-state transformer endeavors to replace the traditional power frequency transformer by means of high frequency isolated AC/AC solid state conversion techniques. SST contains power electronics circuit, can be operated at any frequency.
Due to high-frequency modulation, the volume and weight of SSTs can be much smaller than those of conventional transformers and also allows higher utilization of the magnetic core. SST possess lower physical contours than traditional $50 \mathrm{~Hz}$ transformers and provide active control of power flow. However, difficulty arises due to the inclusion of PEDs as the ancillary services provided by the PEDs which allow two-way power flow, actively change power characteristics such as voltage and frequency levels, improves active and reactive power quality, harmonic filtering, provide efficient routing of electricity based on communication between utility provider and end users and coordination with other transformers in the network.

The idea of an AC-AC high-frequency link, which is the base for the SST concept, was first introduced by W. McMurray in 1968 [1]. Several topologies to realize an SST have been proposed since then in the literature and great efforts have been made to improve their efficiency and performance [2]-[9]. In this work, an attempt has been made to study the design of a proto type, $2 \mathrm{kVA}, 600 / 60 \mathrm{~V}$ SST with operating frequency $20 \mathrm{kHz}$. 


\section{SST Functionalities}

The traditional transformer performs its function very efficiently. However, it is envisioned that future energy systems will demand additional functionalities (besides stepping up/down voltages) that are not achievable with the traditional $50 / 60 \mathrm{~Hz}$ transformer [3], [4]. Examples of these functionalities are the following:

- Active power flow control to achieve reactive power compensation and energy exchange between energy storage elements and the distribution system [4], [5].

- Regulated low-voltage (LV) DC link to facilitate the integration of energy storage systems, renewable energy sources, and DC loads such as DC buildings and future DC grids [3]-[5].

- Voltage sag compensation, fault current limiting, and power quality improvement demanded by the deployment of sensitive loads (e.g., server farms) [4], [5].

- Volume and weight reductions which are critical in applications characterized by space limitations [6]; for example, electric locomotives.

Impact of SST topologies on the HF transformer design SST topologies can be broadly classified in the four categories proposed in [9] and shown in Fig.1; namely, (a) single-stage topology with no DC link, (b) two-stage topology with HV DC link, (c) two-stage topology with LV DC link and (d) three-stage topology.

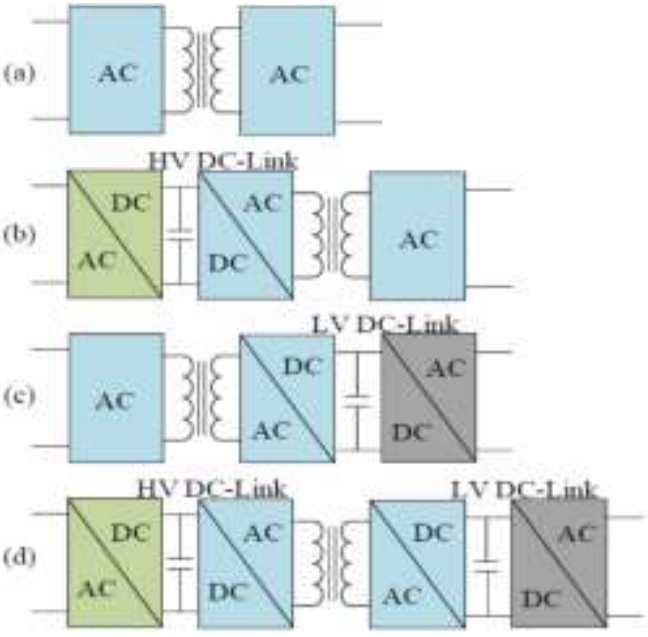

FIGURE 1: Classification of SST Topologies

Topologies under (a) consist of a direct isolated AC-AC stage which might have the lowest cost and simplest approach among the other configurations. In addition, bidirectionality could be possible with four-quadrant switching devices. However, no DC links are available, thus reactive power compensation is not possible. Topologies under (b) consist of an AC-DC conversion stage which provides an HV DC link is combined with a second DC-AC stage with galvanic isolation. Disturbance cancellation and reactive power compensation functionalities are possible with this configuration. The absence of a LV DC link in (a) and (b) makes them improper for applications in distribution systems where easy integration of renewable energies and energy storage elements are desired [10].

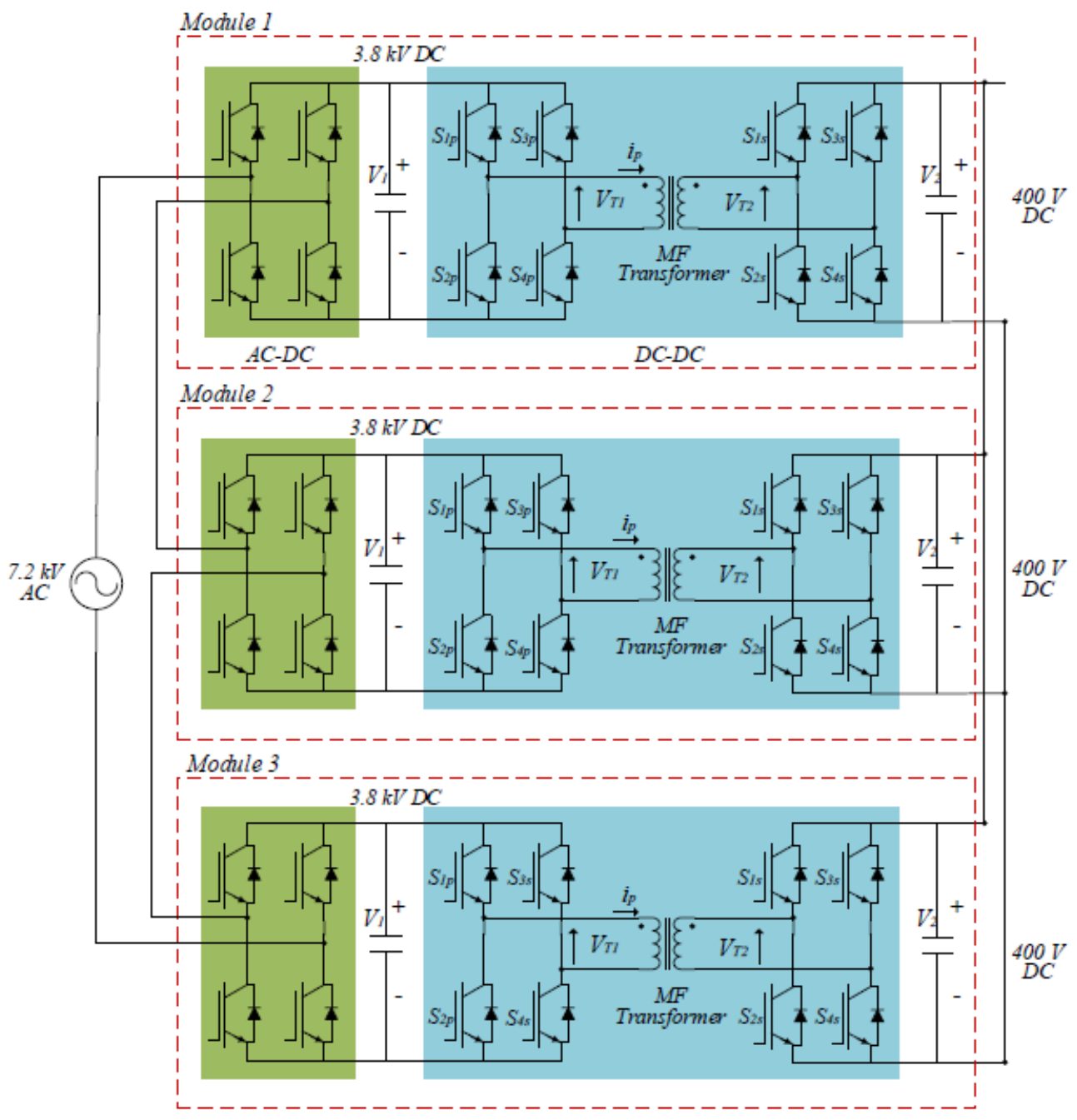

FIGURE 2: SST topologies with full bridges on HV and LV sides 


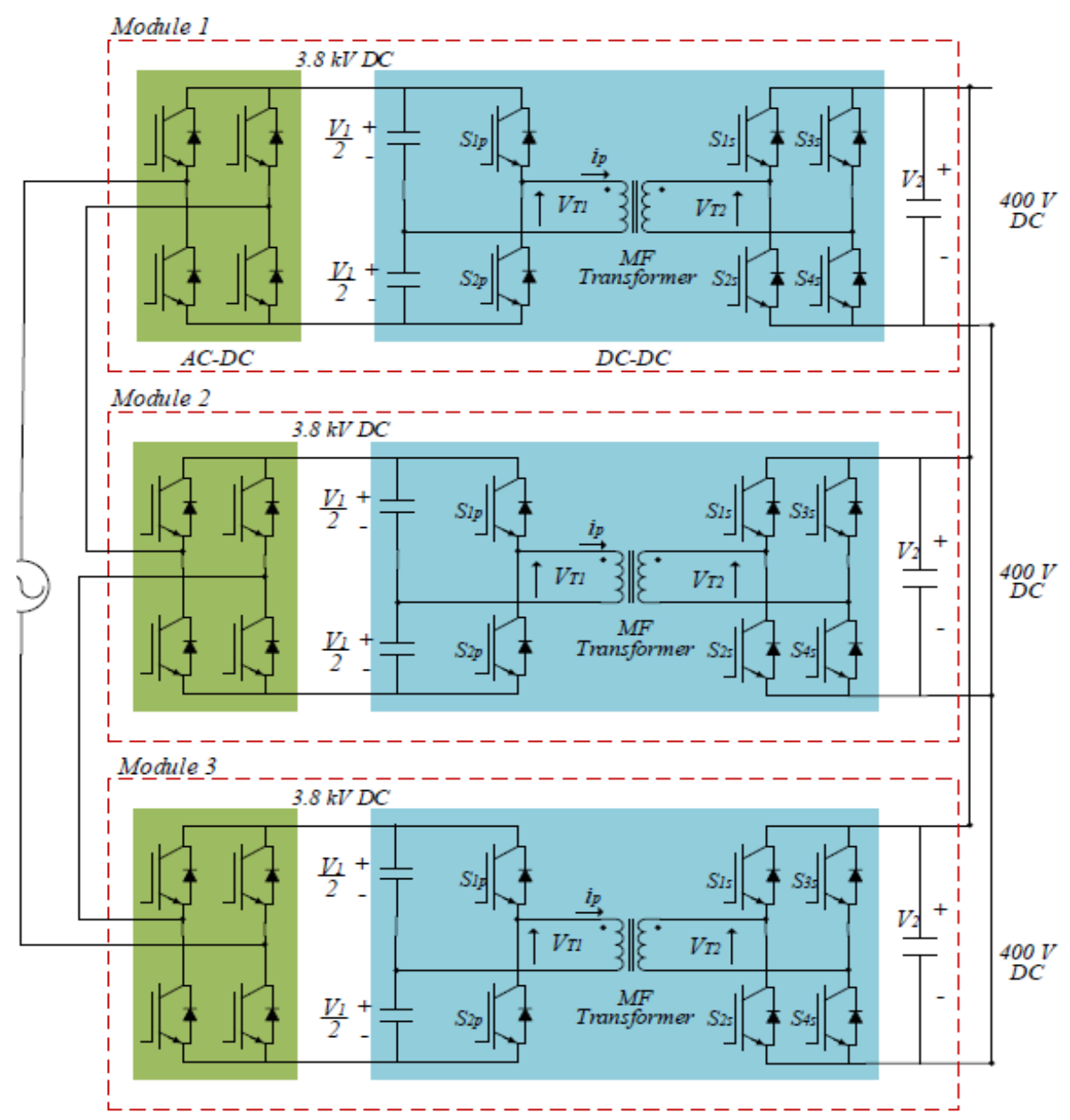

FIGURE 3: SST topologies with half bridges on the HV and full bridge on LV sides

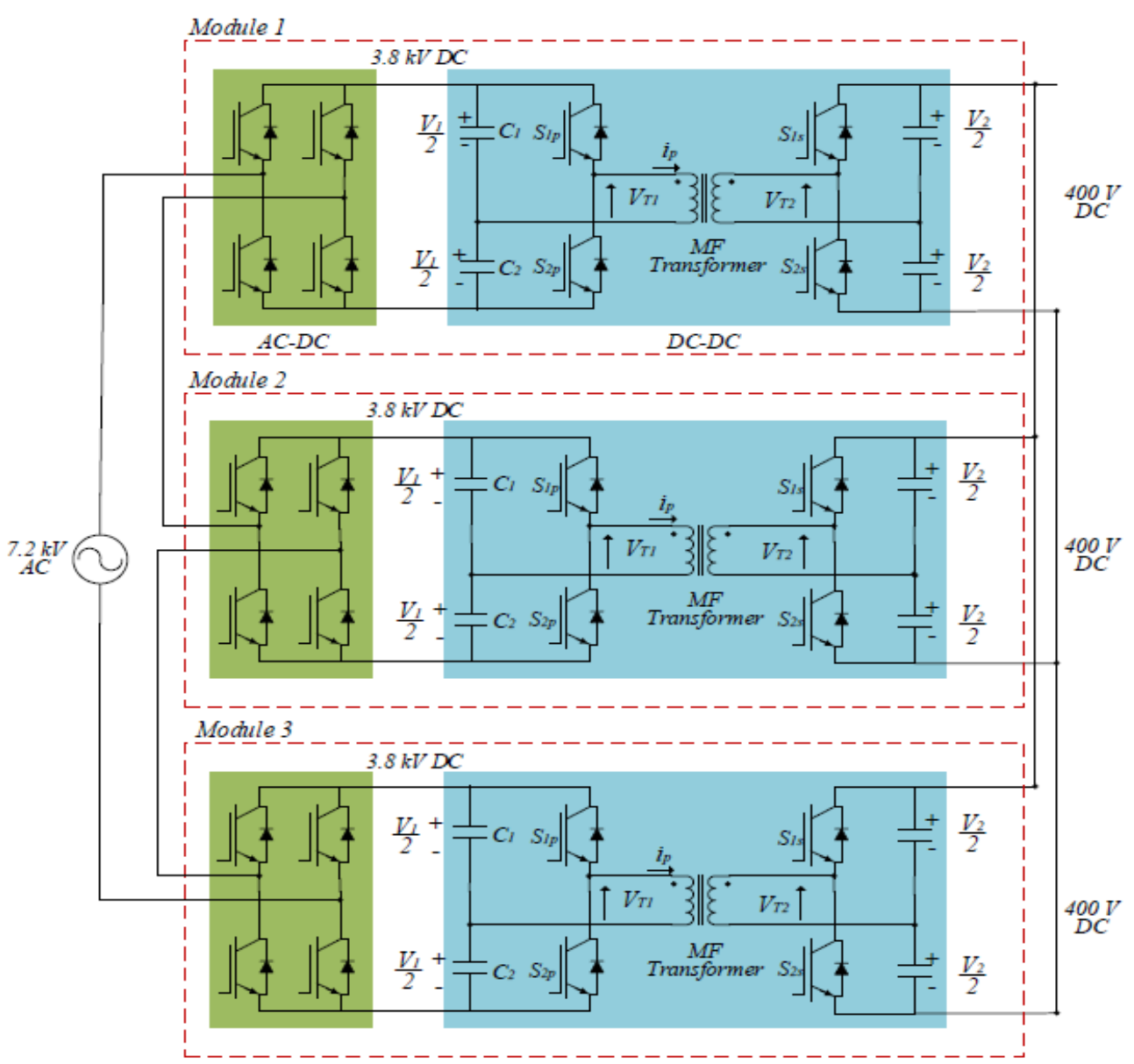

FIGURE 4: SST topologies with half bridges on the HV and LV sides 
Challenges in the High-Frequency Transformer Design The HF/MF transformer in the DC- DC stage performs the same function as the traditional $50 / 60 \mathrm{~Hz}$ transformer which is to enable voltage transformation and provide electrical isolation between HV and LV sides. However, the operation at high voltages and frequencies creates new challenges in the transformer design. High-frequency operation leads to higher core loss and temperature, thus the selection of a magnetic material with high saturation flux density, low specific loss, and high operation temperature is critical to achieve high efficiency and power density. Since reduced volume and weight is a desired feature, isolation requirements and thermal management must be carefully considered. Skin and proximity effects in the windings are significantly increased when compared with the operation at $50 / 60 \mathrm{~Hz}$; therefore, special attention must be paid to the wire selection. The core and winding arrangements must be selected based on the thermal considerations and the leakage inductance requirement for maximum power transfer in the DC-DC stage.

High-Frequency Transformer Design Methodology

There are 10 steps in high frequency SST transformer design methodology. These steps are discussed one after another.

\section{Step 1: System and Topology Specifications}

This step introduces the following system specifications into the program: output power Pout, expected efficiency $\eta$, primary voltage $V_{p}$ and secondary voltage $V_{s}$, operating frequency f, temperature rise $\Delta \mathrm{T}$, and isolation level $V_{\text {iso. }}$. The topology specifications consisting of the duty cycle D and the required leakage inductance $L_{k}$ are introduced

\section{Step 2: Core Material Properties}

Core material selection is critical in a transformer design since it impacts the cost, efficiency and volume. Therefore, it is important to understand the properties of the magnetic materials. In particular, four properties can be used to characterize and properly select a core material suitable for certain application: core loss density $\left(\mathrm{P}_{\mathrm{fe}}\right)$, saturation flux density (Bsat), relative permeability ( $\mu \mathrm{i})$, and Curie temperature.
Typical core magnetic materials considered for highfrequency high-power transformers are ferrite, silicon steel, amorphous, and nanocrystalline. A comparison of selected magnetics materials in terms of the aforementioned properties is listed in Table 1. Ferrite material is commonly used for high-frequency applications since it has relatively low core-loss density and low cost; however, it has low saturation flux density $(\sim 0.4 \mathrm{~T})$, which would result in a heavy and bulky transformer if it is used for high-power applications.

Alternatively, standard silicon steel material has high saturation flux density $(\sim 1.5 \mathrm{~T})$, high permeability, and high Curie temperature which are suitable properties for highpower applications. The main drawback of this material is high core loss density under high-frequency operation due to eddy current losses. For that reason, some manufacturers provide cores made of advanced silicon steel with very thin laminations in order to be used in high- or mediumfrequency applications and minimize eddy current losses. For instance, a transformer rated $2.2 \mathrm{MVA}, 1 \mathrm{kHz}$ was fabricated using silicon steel laminations with a thickness of $0.18 \mathrm{~mm}[9]$.

Amorphous material has gained a lot of interest in highfrequency high-power applications mainly due to its high saturation flux density $(\sim 1.56 \mathrm{~T})$, and much lower coreloss density compared with the standard silicon steel while their costs are comparable. Therefore, amorphous material offers a good balance between cost, efficiency and power density. Finally, the nanocrystalline material shows the best performance in terms of efficiency and power density since it has high saturation flux density $(\sim 1.2 \mathrm{~T})$ and the lowest core-loss density [11]. The core material should be selected based on a material characterization as given in the table 1 . Once the core material is selected, the saturation flux density $B_{\text {sat }}$ and the Steinmetz coefficients $\mathrm{K}, \alpha$ and $\beta$ are obtained from the data provided by the manufacturer and introduced in the program. In addition, the insulation material should be selected and two properties have to be specified, the dielectric strength $E_{\text {ins, }}$, and the safety margin $k_{\text {iso. }}$

TABLE 1: Comparison of Magnetic Material Properties.

\begin{tabular}{|c|c|c|c|c|}
\hline Parameter & $\begin{array}{l}\text { Ferrite } \\
3 C 94[7]\end{array}$ & $\begin{array}{c}\text { Silicon Steel } \\
\text { Amon } 7 \text { \{8] }\end{array}$ & $\begin{array}{l}\text { Amorphous } \\
\text { Metglas } \\
\text { 2605SA1 [10] }\end{array}$ & $\begin{array}{c}\text { Nanocrystalline } \\
\text { Vitroperm 500F } \\
{[11]}\end{array}$ \\
\hline $\begin{array}{c}P_{f e}(W / k g) \\
@ 20 k H z, 0.2 T\end{array}$ & $<18$ & $<400$ & $<40$ & $<8$ \\
\hline$B_{\text {sat }}(\mathrm{T})$ & 0.47 & 1.53 & 1.56 & 1.2 \\
\hline $\mathrm{T}_{\mathrm{c}}\left({ }^{0} \mathrm{C}\right)$ & 220 & 730 & 399 & 600 \\
\hline $\begin{array}{c}\text { Permeability }(\mu) \\
@ 20 \mathrm{kHz}\end{array}$ & $2 \mathrm{k}$ & $16 \mathrm{k}$ & $10 \mathrm{k}-150 \mathrm{k}$ & $20 \mathrm{k}$ \\
\hline
\end{tabular}




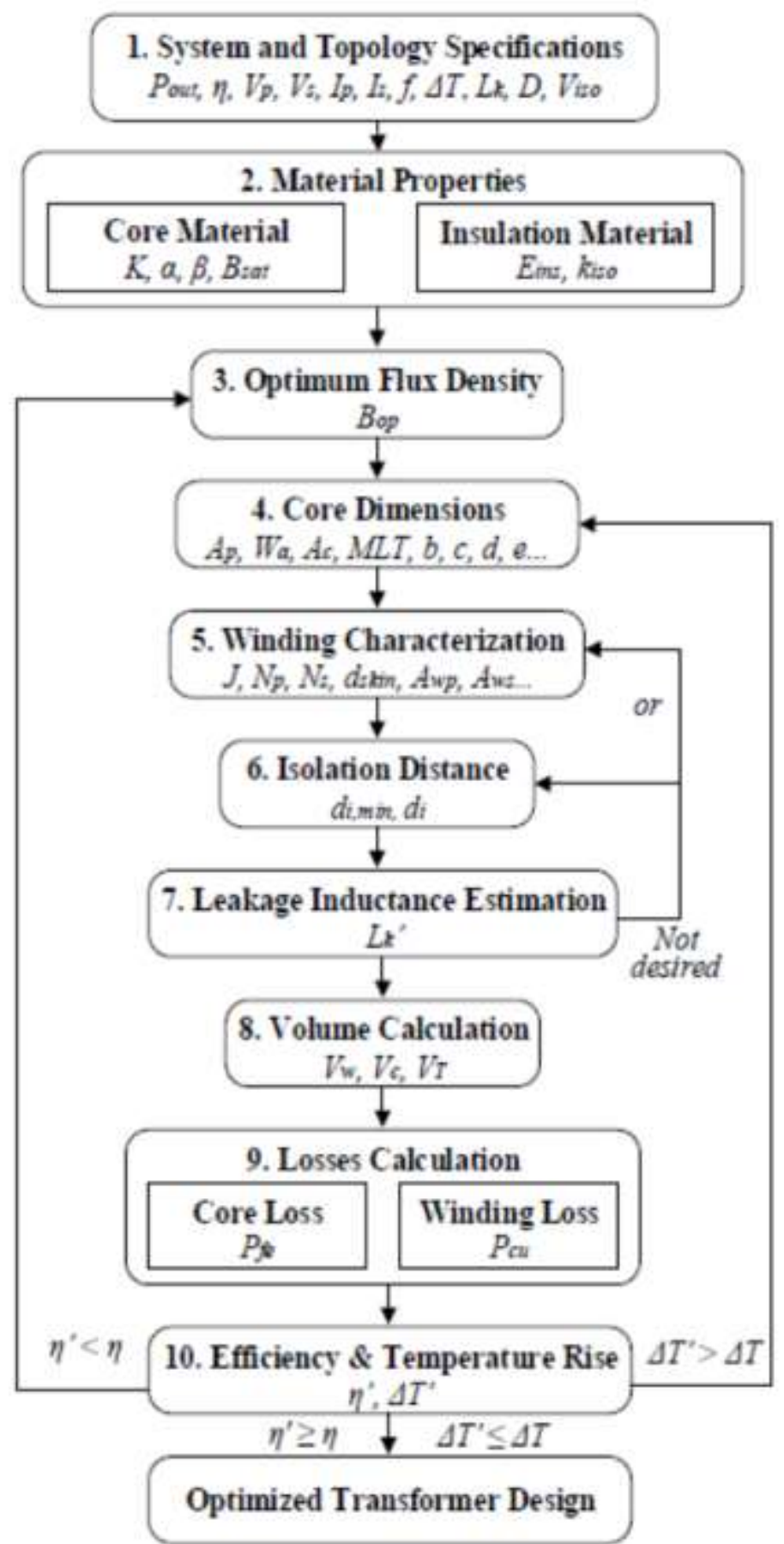

FIGURE 5: Proposed Transformer Design Flowchart

However, the nanocrystalline material has a considerable higher manufacturing cost which limits its use in highpower applications. Moreover, the standard shape of nanocrystalline cores is toroidal tape-wound which imposes a limitation on the transformer construction. Some manufacturers produce special nanocrystalline core shapes with further manufacturing processes; however, the effects of those extra processes on the material properties must be investigated.

Cores made of thin silicon steel laminations, amorphous or nanocrystalline are the most suitable for the considered SST applications. However, the final selection depends on the designer criteria when considering design tradeoffs as represented in Fig.6. For example, if the main design goals are high efficiency and power density, the transformer cost will be compromised. High efficiency could be achieved at a lower cost by decreasing power density.

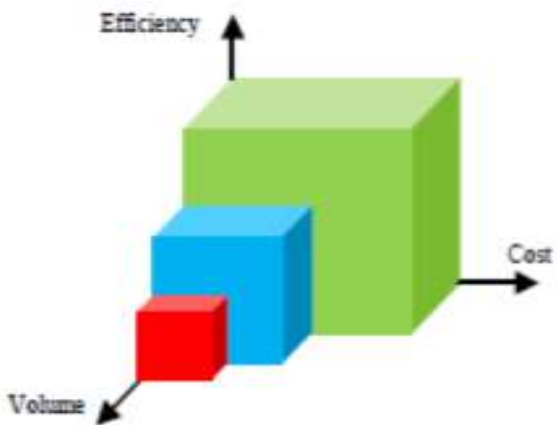

FIGURE 6: Tradeoffs between cost, efficiency, and volume 


\section{Step 3: Optimum Flux Density}

High efficiency is one of the main desired characteristics of the HF/MF transformers for SSTs since the total system loss, unlike the traditional fundamental frequency transformer, will include the transformer losses, as well as the power converter losses (i.e., conduction and switching losses). Therefore, the transformer design procedure must be accompanied of a flux density optimization criterion [1] which has been adopted in this work to maximize transformer's efficiency. The optimization criteria are based on two basic principles: (1) the winding loss or copper loss $\mathrm{P}_{\mathrm{cu}}$ is inversely proportional to the square of the frequency $\mathrm{f}$ and flux density $B$ so,

$$
P_{C U} \alpha \frac{1}{f^{2} B^{2}}
$$

the core loss $P_{f e}$ is proportional to $f$ and $B$ as per the Steinmetz equation:

$$
P_{f e} \alpha f^{\alpha} B^{\beta}
$$

These principles are represented in Figure 2. The total loss $\mathrm{P}_{\mathrm{T}}$ is minimum at point A where it is assumed that the core and winding losses are approximately equal; hence, the starting point of the optimization criteria.

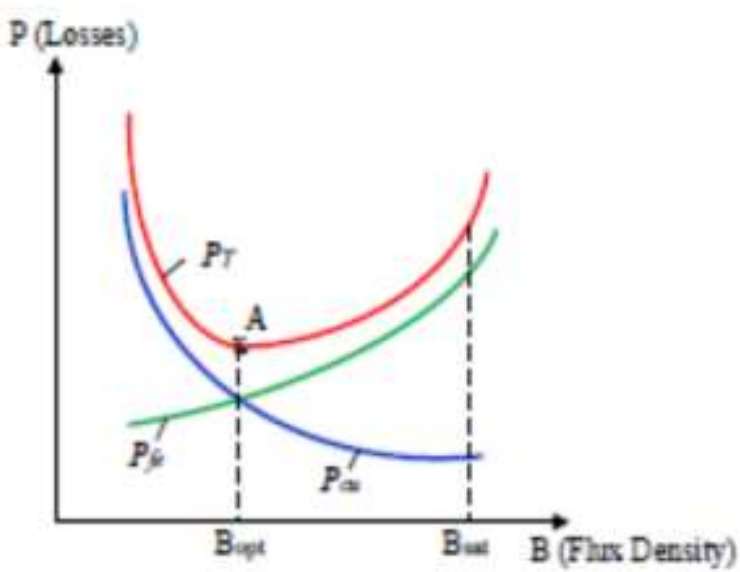

FIGURE 7: Optimum Flux Density representation

Based on the aforementioned principles, the following equation to calculate the optimum flux density $B_{\text {opt }}$ at point A was developed in [1], [5]:

$B_{O p t}=\frac{\left[h_{c} K_{a} \Delta T\right]^{2 / 3}}{2^{2 / 3}\left[\rho_{w} K_{w} K_{u}\right]^{1 / 2}\left[K_{C} K f^{\alpha}\right]^{7 / 12}}\left[\frac{K_{v} f K_{f} K_{u}}{\Sigma V A}\right]$

where $\rho_{w}$ is the wire resistivity; $k_{a}, k_{c}, k_{w}$, are dimensionless coefficients obtained from dimensional studies of different types of cores [1]; $h_{c}$ is the coefficient of heat transfer; $k_{u}$ the window utilization factor; $\sum V A$ the total transformer power rating; $\Delta \mathrm{T}$ the temperature rise; $K_{v}$ the waveform factor which depends on the shape of the voltage waveform applied to the windings; and $K_{f}$ is the stacking factor which relates the effective cross-sectional area with the physical area of the core. Typical values of the coefficients and factors necessary to calculate $B_{\text {opt }}$ will be given in the next section that presents the transformer design methodology proposed in this work. The optimum flux density $B_{o p t}$ is now calculated. Typical values of the dimensionless coefficients in (3) are $k_{a}=40, k_{c}=5.6$, and $k_{w}=10$ [2] and are set as fixed parameters. For natural convection, the coefficient of heat transfer $h_{\mathrm{c}}$ is typically 10 $\mathrm{W} / \mathrm{m}^{2}-{ }^{\circ} \mathrm{C}$ however, this value may change depending of the type of cooling. The window utilization factor $k u$ can vary from 0.2 to 0.8 , being 0.8 a value for a very tight winding and 0.4 a recommended value [6]. The stacking factor $k_{f}$ relates the effective cross-sectional area of the core with the physical area; its value can be around 0.95 for laminated cores. The waveform factor is $K_{v}=4.44$ is considered for a sinusoidal waveform and $K v=4$ for a square waveform [2] [4]. If a different voltage waveform is applied, $K v$ can be derived as explained in [1]. The optimal flux density Bopt is compared with the Bsat. The calculated value of Bopt could be well below Bsat; therefore, the designer can choose to increase the operating flux density to a value that does not affect considerably the efficiency but can increase power density. This recalls the tradeoffs between efficiency and volume.

\section{Step 4: Core Dimensions}

The core size is selected based on the area product $A_{p}$ which is a relationship that can be found in any manufacturer's datasheet and is the product between the window area and the cross-sectional area of a core. The expression to calculate $A_{p}$ derived in [1] is given by:

$$
A_{p}=\left[\frac{\sqrt{2}}{K_{v}} \frac{\Sigma V A}{f B_{o} K_{f} K_{t} \sqrt{k_{u} \Delta T}} \quad\right]^{8 / 7}
$$

where $K_{t}$ is obtained as follows [1]

$$
K_{t}=\sqrt{\frac{h_{c} k_{a}}{\rho_{w} k_{w}}}
$$

With the value of $A_{p}$ the designer has to identify in a datasheet a core with a larger $A_{p}$ than the calculated one. If the larger core in the datasheet is not sufficient, stacked cores can be used to complete the desired $A_{p}$. The designer can enter the required number of cores and choose if the core arrangement is core type or shell type. After the core is selected, the designer can enter the core dimensions and properties from the datasheet. The designer can change the core dimensions in a second iteration if the evaluated temperature rises in step 10 exceeds the desired value. In practice, only about $50 \%$ of the window area can actually carry active conductor, this fraction is called the fill factor. In a two-winding transformer, this means that each winding can fill not more than $25 \%$ of the total wire winding window area

\section{Step 5: Winding Characterization}

Having selected the core, the designer can now select the wire based on the current density [1]:

$$
J_{0}=K t \sqrt{ }\left(\frac{\Delta T}{2 K_{u}}\right) \cdot \frac{1}{\sqrt[8]{A_{p}}}
$$

The value of $J_{0}$ and the primary and secondary currents are used to calculate the required primary and secondary bare wire areas, respectively. Also, the HF effects on the windings are considered by using Litz wire; therefore, the skin depth is calculated as:

$$
\delta=\frac{1}{\sqrt{\pi f \mu_{0} \sigma}}
$$

For copper conductors, the skin depth is given by [1]

$$
\delta=\frac{6.6}{\sqrt{f}}
$$

An equation that gives an approximate value of $\mathrm{R}_{\mathrm{AC}}$ of a round conductor of radius $r_{o}$ can be derived [1]:

$$
R_{A C}=R_{D C}\left[1+\frac{\left(r_{0 / \delta}\right)^{4}}{48+0.8\left(r_{0 / \delta)}\right.}\right]
$$


The DC resistance $\mathrm{R}_{\mathrm{DC}}$ of the windings considering a conductor carrying a DC current or a low frequency AC current can be determined by:

$$
R_{D C}=\frac{N \rho \cdot M L T}{A w}
$$

where $\mathrm{N}$ is the number of turns of the winding, $\rho$ is the specific resistance of the conductor, MLT is the mean-length of a turn, and Aw is the conductor cross-sectional area. In order to reduce the skin and proximity effects in the windings, a stranded wire with insulated strands named Litz wire is commonly used.

Subsequently, the primary number of turns $N_{p}$ is calculated from [2]:

$$
N_{P}=\frac{V_{P}}{K_{v} K_{f} A_{c} B_{o p t} f}
$$

where $A_{c}$ is the core cross-sectional area. The secondary number of turns $N_{s}$ is obtained with the voltage transformation ratio,

$$
\mathrm{a}=\frac{N_{p}}{N_{S}}=\frac{V_{P}}{V_{S}}
$$

The number of turns is a free parameter in this design methodology since it can be used to adjust the transformer leakage inductance; therefore, in subsequent iterations the designer can change the number of turns.
Then, it is necessary to verify that the winding arrangement (i.e., wire size and number of turns) can actually fit in the core window area.

\section{Step 6: Isolation Distance}

Since the SST is being proposed as a replacement of the traditional transformer, it must be in compliance with the international standards related to the requirements for distribution and power transformers, for example, the ANSI/IEEE C57.12.01. One of those requirements is the isolation level based on the transformer excitation voltage. This is a design consideration that must be included in the design since it will have a significant impact on the transformer power density. The isolation level is included within the transformer design through the calculation of a minimum isolation distance given by [3], [10]:

$$
d_{\min }=\frac{V_{\text {iso }}}{K_{\text {iso }} E_{\text {ins }}}
$$

where $V_{\text {iso }}$ is the isolation voltage level, $E_{\text {ins }}$ is the dielectric strength of the insulation material, and $\mathrm{K}_{\mathrm{iso}}$ is a safety margin given by some manufacturers or chosen based on the designer criteria. Properties of typical dry-type

\begin{tabular}{|c|c|c|c|}
\hline Dielectric material & $\begin{array}{l}\text { Thermal conductivity } \\
\left(\mathrm{W} / \mathrm{m}^{\circ} \mathrm{K}\right)\end{array}$ & $\begin{array}{l}\text { Dielectric strength } \\
E_{\text {ins }}(\mathrm{kV} / \mathrm{mm})\end{array}$ & Dissipation factor $(\tan \delta)$ \\
\hline Air & 0.03 at $70^{\circ} \mathrm{C}$ & 3 & 0 \\
\hline EPOXI & 0.25 & 15 & 0.02 at $100 \mathrm{kHz}$ \\
\hline Mica & 0.71 & 11.43 & - \\
\hline NOMEX & 0.175 at $150^{\circ} \mathrm{C}$ & 27 & 0.005 at $60 \mathrm{~Hz}$ \\
\hline
\end{tabular}
dielectric materials used in transformers are listed in Table 2 .

TABLE 2: Properties of typical dry-type dielectric materials used in transformers

The isolation voltage and insulation material have been specified in steps 1 and 2 .

\section{Step 7: Leakage Inductance Estimation}

This step estimates the transformer leakage inductance that will result from the design and repeated here for completeness [1]-[3]:

$$
L_{k}=\mu_{0} N^{2} M L T \cdot\left(\frac{a+b+3 c}{3 w}\right)
$$

This equation is only applicable to a shell-type transformer structure. If a core-type structure is desired, 2D or 3D finite element simulations would be required to obtain a more accurate value of leakage inductance. If the desired leakage inductance for maximum power transfer is not achieved, the proposed design allows two parameters to change in order to adjust the leakage inductance, the number of turns or the isolation distance. These parameters can be changed in a subsequent iteration.

\section{Step 8: Volume Calculation}

Achieving high power density might be the priority in some cases, but there might be others where the efficiency is more important than power density; hence, this step is useful to provide an estimation of the transformer volume. Then, the designer can evaluate if the result is acceptable or not. The equations to calculate the core volume $V_{\mathrm{c}}$ and winding volume $V_{\mathrm{w}}$ are the following [1], [2]:

$$
\begin{aligned}
V_{\mathrm{c}} & =l_{m} A_{c} \\
V_{\mathrm{w}} & =M L T . W_{\mathrm{a}}
\end{aligned}
$$

where $l_{m}$ is the mean length of the core and $M L T$ is the Mean Length of a Turn.

\section{Step 9: Losses Calculation}

The total losses are split into core and winding losses. Analytical calculation of losses in Litz wire is also explained in [4]. Several approaches to determine the core losses have been proposed in the literature [13]-[15]. Other approaches are based on hysteresis modeling such as the Preisach model and Jiles-Atherton model [14]. Although those approaches can be very accurate, extensive calculations and measurements are required in order to get a core loss estimation [15]. Therefore, empirical equations based on measured data are more commonly used to estimate core losses [5], [14], [15]. Particularly, a widely used equation is the Original Steinmetz Equation (OSE): $P_{v}=K f^{\alpha} B_{m}^{\beta}$

where $\mathrm{P}_{\mathrm{v}}$ is the time-average power loss per unit volume; $K, \alpha$ and $\beta$ are material parameters obtained from manufacturer's datasheet or determined by curve fitting the material loss curve under sinusoidal excitation; and $B_{m}$ is the maximum flux density resulting from an excitation voltage with frequency $f$. Several modifications to the OSE have been proposed to overcome this limitation [15]. For instance, the Modified Steinmetz Equation (MSE) relates the rate of change of the flux density $(\mathrm{d} B / \mathrm{dt})$ to the core losses and replace the frequency $f$ in the OSE for an equivalent frequency $f_{e q}$.

\section{Step 10: Efficiency and Temperature Rise}

Once the losses are calculated, the efficiency is evaluated and compared with the expected efficiency specified in 
step 1. The designer can discard the results and start a new design process if the efficiency requirement is not fulfilled. The operating flux density can be used as free parameter to start the new design process or the designer can consider the use of a different core material with lower core loss density.

Another important parameter to evaluate is the resulting temperature rise to verify that the predefined temperature rise is not exceeded. A valid assumption to estimate the temperature rise is that the heat produced by the core and winding losses is dissipated uniformly throughout the transformer surface area. Based on that assumption, an equation to estimate the temperature rise $\Delta T$ can be written as [5]:

$$
\Delta T=\left(\frac{P_{t}}{A_{t}}\right)^{0.833}
$$

Where, $A_{t}=K_{s} \sqrt{A_{p}}$

$K_{s}=39.2$ is assumed for core for C cores [3]. If the calculated value of temperature rise exceeds the predefined value, a new set of core dimension parameters should be used. Another option is to perform a thermal analysis in order to implement an appropriate cooling system that also allows a compact transformer design.

Design Considerations: $2 \mathrm{kVA}, 20 \mathrm{kHz}, 600 / 60 \mathrm{~V}$, shelltype transformer.

In present study the design of a transformer with a power rating of $2 \mathrm{kVA}$, operating frequency of $20 \mathrm{kHz}$, and voltage rating of $600 / 60 \mathrm{~V}$ as a scaled-down prototype used for testing new power converter topologies for SSTs [13].

Step 1: System and Topology Specifications

TABLE 3: Parameters and desired specifications of a proto type shell type transformer

\begin{tabular}{|c|c|}
\hline Parameters & Desired/specified values \\
\hline Rated output power & Pout $=2 \mathrm{kVA}$ \\
\hline Expected Efficiency & $\eta \geq 98 \%$ \\
\hline Primary voltage & $V p=600 \mathrm{~V}$ \\
\hline Secondary voltage & $V s=60 \mathrm{~V}$ \\
\hline Isolation voltage & $V_{\text {iso }}=1.0 \mathrm{kV}$ \\
\hline Primary current, & $I_{p}=4 \mathrm{~A}$ \\
\hline Secondary current & $I_{s}=40 \mathrm{~A}$ \\
\hline Frequency & $f=20 \mathrm{kHz}$ \\
\hline Ambient temperature & $T_{a}=25^{\circ} \mathrm{C}$ \\
\hline Expected temperature rise & $\Delta T=60^{\circ} \mathrm{C}$ \\
\hline Duty cycle & $D=0.5$ \\
\hline Waveform factor & $K_{v}=4$ \\
\hline Leakage inductance & $L_{k}=1.1 \mathrm{mH}$ \\
\hline Window utilization factor & $k_{u}=0.4$ \\
\hline
\end{tabular}

\section{Step 2: Material Properties}

Amorphous 2605SA1 core is selected due to its lower cost and greater availability compared with nanocrystalline core. The selected insulation material is MICA with a dielectric strength of $15 \mathrm{kV} / \mathrm{mm}$ and a safety margin of $40 \%$ [4].

\section{Step 3: Optimum Flux Density}

Optimum flux density is calculated by using Equation (3) as $B_{\text {opt }}=0.144 \mathrm{~T}$. The specified operating flux density is then $0.15 \mathrm{~T}$.

\section{Step 4: Core Dimensions}

The resulting area is $A_{p}=32.83 \mathrm{~cm}^{4}$ and the core AMCC-50 with $A_{p}=45.9 \mathrm{~cm}^{4}$ is chosen for this design [6]. Since it is desired to build the transformer with a shell-type configuration, two sets of C-cores may be used. The resulting area product is then $A_{p}=184.8 \mathrm{~cm}^{4}$.

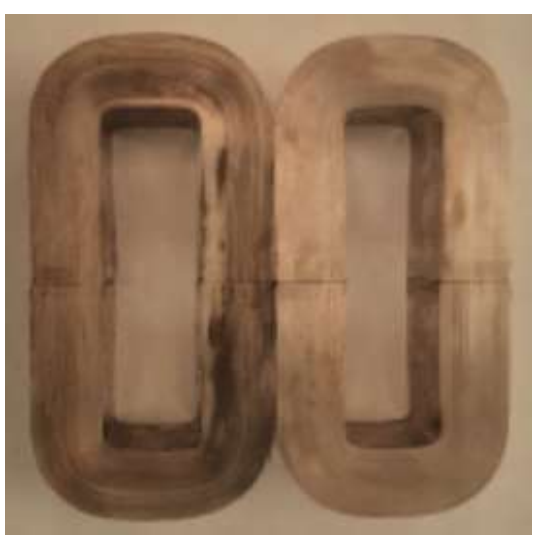

FIGURE 8: Two sets of C-cores AMCC-50 in a shell-type configuration 


\section{Step 5: Winding Characterization}

The calculated current density according to the previous specifications is $J=2178.5 \mathrm{~A} / \mathrm{cm}^{2}$. Then, the primary and secondary bare wire areas are $A_{w p}=0.0184 \mathrm{~cm}^{2}$ and $A w s$ $=0.1839 \mathrm{~cm}^{2}$ respectively. The maximum allowable area that is used to choose the strands size is $0.0069 \mathrm{~cm}^{2}$ according to a skin depth of $\delta=0.0468 \mathrm{~cm}$ at $20 \mathrm{kHz}$. The Litz wire $36 \mathrm{AWG} / 259$ equivalent to $12 \mathrm{AWG}$ is selected because it meets the requirements and is available in the market. The strands of the selected Litz wire have an area of $0.1266 \times 10^{-3} \mathrm{~cm}^{2}$ and a resistivity at $20^{\circ} \mathrm{C}$ of 13608 $\mu \Omega / \mathrm{cm}$. The selected wire is also used for the secondary winding with six of them in parallel. The number of turns in the primary winding is $N_{p}=80$ and in the secondary is $N_{s}=8$. So, transformation ratio $\mathrm{K}=8 / 80=0.1$. The primary DC resistance for $1 \mathrm{~cm}$ length of litz wire is $R_{1}(d c)=$ $\frac{13608}{0.1266 \times 10^{-3}} \times 1=107.48 \mu \frac{\Omega}{\mathrm{cm}}=\frac{0.0107 \Omega}{\mathrm{m}}$ per strand. Due to the skin effect and the proximity effect, the coil resistance increases with the increase in the frequency [14]. So, we choose $50 \%$ increase of resistance in high frequency ac. The primary ac resistance becomes $R_{1}(a c)=0.01605 \Omega / \mathrm{m}$. The secondary has 6 strands connected in parallel. Hence, $R_{2}(a c)=\frac{1}{6}\left[R_{1}(a c) K^{2}\right]=1.78 \times 10^{-5} \Omega / \mathrm{m}$.

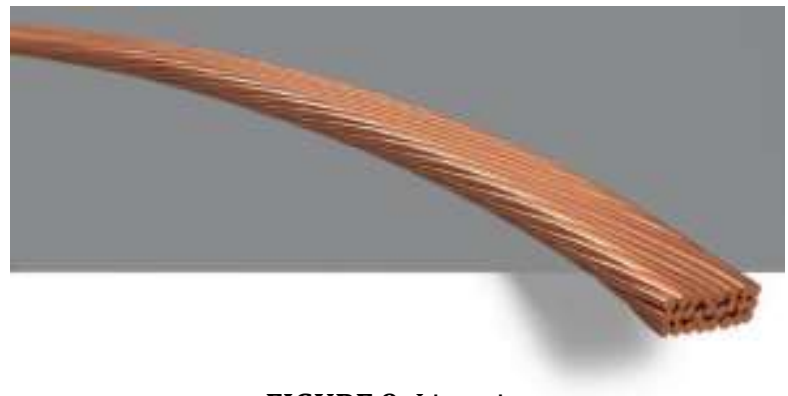

FIGURE 9: Litz wire

[Elektrisola Dr. Gerd Schildbach GmbH\&Co.KG]

\section{Step 6: Isolation Distance}

The minimum isolation distance between windings for an isolation level of $1 \mathrm{kV}$ is $d i$, $\min =0.17 \mathrm{~mm}$, thus $0.20 \mathrm{~mm}$ is considered [13].

\section{Step 7: Leakage Inductance Estimation}

The estimated leakage inductance is $1.9 \mathrm{mH}$, therefore, there is no need to adjust the isolation distance or number of turns to meet the leakage inductance requirement.

\section{Step 8: Volume Calculation}

The volume is calculated by using Equation (15) and (16). The estimated core volume is $V_{T}=0.71 \mathrm{dm}^{3}$.

\section{Step 9: Losses Calculation}

The operation of the transformer at specified condition results core loss $P_{f e}=101.91 \mathrm{~W}$ and winding loss is $P c u=$ $4.42 \mathrm{~W}$; thus, the total transformer loss is $P_{T}=106.33 \mathrm{~W}$.

\section{Step 10: Efficiency and Temperature Rise}

The transformer efficiency is $\eta=95 \%$ and the temperature rise is $\Delta T=82.4{ }^{\circ} \mathrm{C}$ for natural convection [4]. The main specifications are listed in Table 2 . The desired efficiency was not achieved because it was not possible to build the transformer with the optimum parameters since it was necessary to consider low-cost materials and only the cores available in stock in order to get a shorter lead time [4]. Here, one should select proper Litz wire according to the optimum conditions.

\section{CONCLUSION}

Each step of the proposed transformer design methodology and the principles for the optimization criteria are described in this work. The design methodology is oriented towards obtaining the highest efficiency by calculating the optimum flux density at which the core losses and the copper losses are equal. However, the design is mainly driven by power density and not by the efficiency. The flux density can be modified according to the desired outcome. In addition, the design methodology includes the estimation of the leakage inductance for shell-type transformer configurations. Litz wires are used for the design to reduce the skin effect and proximity effect losses in conductors used at frequencies about $20 \mathrm{kHz}$.

\section{REFERENCES}

[1] W. G. Hurley, W.H. Wölfle, Transformers and Inductors for Power Electronics: Theory, Design and Applications, 1st ed., Wiley, 2013.

[2] F. Krismer, J. W. Kolar, "Efficiency-optimized highcurrent dual active bridge converter for automotive applications," IEEE Transactions on Industrial Electronics, vol. 59, no. 7, Jul. 2012.

[3] X. She, R. Burgos, G. Wang, F. Wang, A.Q. Huang, "Review of solid-state transformer in the distribution system: From components to field application," in Proceedings of the IEEE Energy Conversion Congress and Exposition, ECCE 2012, pp. 4077-4084, Sept., 2012.

[4] R. J. Garcia Montoya, A. Mallela, J. C. Balda, "An evaluation of selected solid-state transformer topologies for electric distribution systems," in Proceedings of the IEEE 30th Applied Power Electronics Conference and Exposition, APEC 2015, pp. 1022-1029, March 2015.

[5] C. William, T. McLyman, Transformer and Inductor Design Handbook, 4th ed., Taylor \& Francis Group, 2011.

[6] R. Garcia, A. Escobar-Mejía, K. George, J. C. Balda, "Loss comparison of selected core magnetic materials operating at medium and high frequencies and different excitation voltages," in Proceedings of the IEEE 5th International Symposium on Power Electronics for Distributed Generation Systems, PEDG 2014, pp. 1-6, June 2014.

[7] S. Xu, Y. Xunwei, F. Wang, A. Q. Haung, "Design and demonstration of $3.6 \mathrm{kV}-120 \mathrm{~V} / 10 \mathrm{kVA}$ solid-state transformer for smart grid application," IEEE Transactions on Power Electronics, vol. 29, no. 8, pp. 3982-3988, Aug 2014.

[8] S. Falcones, X. Mao, R. Ayyanar, "Topology Comparison for Solid State Transformer Implementation," IEEE Power and Energy Society General Meeting, pp. 1-8, July 2010.

[9] L. Heinemann and G. Mauthe, "The universal power electronics-based distribution transformer, a unified approach," in Proceedings of the IEEE 32nd Annual Power Electronics Specialists Conference, PESC, vol. 2, pp. 504-509, 2001.

[10] G. Ortiz, J. Biela, J. W. Kolar, "Optimized design of medium frequency transformers with high isolation requirements," in Proceeding of the 36th IEEE Industrial Electronics Society Conference, IECON 2010, pp. 631-638, Nov. 2010. 
[11] [Online]Available:

http://www.dupont.com/content/dam/assets/prod ucts-and-services/electronic-electricalmaterials/assets/DPP_Nomex410_K20612-1.pdf April 2015]

[12] [Online] Available: Cooner Wire, "Type 8 rectangular litz," http://www.newenglandwire.com/products/litzwire-and-formed-cables/round [Accessed May 2015].

[13] R. J. Garcia Montoya, A. Mallela, J. C. Balda, "An evaluation of selected solid-state transformer topologies for electric distribution systems," in Proceedings of the IEEE 30th Applied Power Electronics Conference and Exposition, APEC 2015, pp. 1022-1029, March 2015.
[14] Q. Deng, J. Liu, D. Czarkowski and M. Kazimierczuk, "Frequency Dependent Resistance of Litz-Wire Square Solenoid Coils and Quality Factor Optimization for Wireless Power Transfer" EEE Transactions on Industrial Electronics, Vol.63(5), May 2016.

[15] H.H.H. De Silva, D.K.J.S. Joyamaha and L.W. Archchchige, "Review on design and control of solidstate transformer based microgrids", AIMS Energy, 7(6): 901-923, December 2019.

[16] http://www.aimspress.com/journal/energy Dr. Raton Kumar Nondy and Prema Nondy, "Solid State Transformer (SST) For Smart Application in Power System", AJER, Volume-10, Issue-6, pp-32-41, 2021. 